\section{PP.80 IDENTIFYING RESEARCH UNCERTAINTIES ABOUT PRETERM BIRTH WITH CLINICIANS AND SERVICE USERS}

doi:10.1136/archdischild-2013-303966.355

1S Uhm, ${ }^{2} \mathrm{D}$ Brady, ${ }^{3} \mathrm{~S}$ Carroll, ${ }^{4} \mathrm{~B}$ Chambers, ${ }^{5} \mathrm{Z}$ Chivers, ${ }^{6} \mathrm{~S}$ Crowe, ${ }^{7} \mathrm{AL}$ David, ${ }^{8} \mathrm{~S}$ Deshpande, ${ }^{9}$ Dowling-Brady, ${ }^{10} \mathrm{~L}$ Duley, ${ }^{11} \mathrm{C}$ Gale, ${ }^{12} \mathrm{G}$ Gyte, ${ }^{13} \mathrm{CP}$ James, ${ }^{14} \mathrm{~J}$ Jeffrey, ${ }^{15} \mathrm{~J} \mathrm{McNeill,}{ }^{16} \mathrm{MA}$ Turner, ${ }^{17} \mathrm{~A}$ Shennan, ${ }^{18} \mathrm{~S}$ Oliver. 'Social Science Research, Unit Institute of Education, University of London, London, UK; ' $T$ TinyLife - the premature baby charity for UK, Carryduff, UK; ${ }^{3}$ Cleft Lip and Palate Association, London, UK; ${ }^{4}$ Tavistock Clinic, London, UK; ${ }^{5} B$ liss - the premature and special care baby charity, London, UK; ${ }^{6}$ James Lind Alliance, Oxford, UK; ' UCL Institute for Women's Health, London, UK; ${ }^{8}$ Royal Shrewsbury Hospital, Shrewsbury, UK; 9/rish Premature Babies, Dublin, Ireland; ${ }^{10}$ Nottingham Clinical Trials Unit, University of Nottingham, Nottingham, UK; " ${ }^{\text {Academic }}$ Neonatal Medicine, Imperial College London, London UK; ${ }^{12}$ National Childbirth Trust (NCT), London, UK; ${ }^{13} \mathrm{UCL}$ Institute for Women's Health, London, UK; ${ }^{44}$ British and Irish Paediatric Pathology Association, UK and Republic of Ireland; ${ }^{15}$ School of Nursing \& Midwifery, Belfast, UK; ${ }^{16}$ Liverpool Women's NHS Foundation Trust, Liverpool, UK; ${ }^{17}$ Kings College London, London, UK; ${ }^{18}$ Social Science Research Unit, Institute of Education, University of London, London, UK

Preterm infants have immature internal organs and often need help with breathing, feeding, and other life support. Those who survive may suffer ill health or disability in childhood, which could potentially continue to adulthood. Even modest improvement for these infants and their families would be important. Clinical research may not fully address the uncertainties in treatment and care that are of greatest importance to service users and clinicians. This research adapted a mixed-method approach developed by the James Lind Alliance to establish Priority Setting Partnerships (PSP). We recruited 44 clinical and service users' organisations across UK and Ireland from April 2011 and formed a Steering Group (SG). An on-line survey was conducted from March to September 2012. A total number of 1,050 participants started the survey, while 343 of them (service users: $57 \%$, clinicians: $30 \%$ and both $12 \%$ ) suggested about 200 research unique uncertainties. While we received feedback from clinicians of various specialities (neonatologist: 28\%, nurse: 25\%. obstetrician: 18\%, midwife: $12 \%$ and others $10 \%)$. Most service users were white British and middle class. Service users asked about aetiologies, interventions and outcomes for pre-pregnancy (12), antenatal (42), perinatal (18), postnatal (58) and other care (20), revealing interests in a broad range of issues surrounding preterm birth. If research agendas are to serve the interests of service users at higher risk of preterm birth there is a need to improve ways of engaging service users from ethnic minorities and disadvantaged backgrounds.

\section{PP.81 PREGNANCY AFTER PREVIOUS STILLBIRTH}

doi:10.1136/archdischild-2013-303966.356

ME Geisler, K O'Donoghue. Department of Obstetrics and Gynaecology, Cork University Maternity Hospital, University College Cork, Cork, Ireland

One in 200 pregnancies ends in stillbirth. The subsequent pregnancy requires increased surveillance and intervention. We aimed to examine management of this pregnancy with maternal and neonatal outcomes.

A retrospective cohort study of subsequent pregnancies in women who had a stillbirth from 2007 to 2011.

One hundred women were identified in a new pregnancy. Median maternal age was 32 years (range 20-44). Median gestational age at prior stillbirth (infant $>500$ g) was 34 weeks (range $22+6-41+4$ ). $25 \%$ of the stillbirths were classified as unexplained and $23 \%$ were due to a congenital abnormality. Nineteen women (19/100; 19\%) had a first trimester miscarriage. Seven women were diagnosed with gestational diabetes $(7 / 81 ; 9 \%)$ and six developed gestational hypertension $(6 / 81 ; 7 \%)$. Median number of antenatal clinic attendances was ten (range 3-21) and median number of ultrasound examinations was six (range 1-22). One woman experienced a stillbirth at
26 weeks due to recurrent non-immune hydrops, two had a preterm placental abruption, and three developed early-onset fetal growth restriction. Eight women $(8 / 81 ; 10 \%)$ delivered preterm (28-36 weeks). The remainder had a term delivery $(37+0-40+5$ weeks). Of these, $11(11 / 73 ; 15 \%)$ had an elective caesarean section (CS), and $41(41 / 73 ; 56 \%)$ underwent induction of labour, with $81 \%$ delivering vaginally. Eleven infants were admitted to the neonatal intensive care unit, but there were no significant morbidities.

Pregnancy after stillbirth results in increased medical intervention and a demand on hospital resources. Both can be justified but are of unproven medical benefit. Here, the majority of women delivered a liveborn infant after an uncomplicated pregnancy.

\section{PP.82 DOES USE OF ENDO-ANAL ULTRASOUND EFFECT THE MANAGEMENT OF WOMEN WHO HAVE SUSTAINED A 3A TEAR?}

doi:10.1136/archdischild-2013-303966.357

'S Harrison, ${ }^{2} \mathrm{D}$ Farrar, ${ }^{1} \mathrm{~K}$ Wilkinson, ${ }^{1} \mathrm{C}$ Ramage. 'Bradford Women's and Newborn Unit, Bradford, UK; ${ }^{2 B}$ radford Institute for Health Research, Bradford, UK

Introduction Third degree tears complicate 1.7 to $18 \%$ of vaginal births. Although many women are asymptomatic by twelve month follow-up, there is concern regarding management of future pregnancies, particularly mode of birth. It has been suggested that lesions identified by endo-anal ultrasound (EAUS) and the presence of symptoms can be used to inform decision making about mode of birth in subsequent pregnancies. We aimed to ascertain the incidence of $3 \mathrm{~A}$ tears, the proportion with symptoms and/or observable sphincter defects using EAUS and mode of birth in subsequent pregnancies. Method A Retrospective three year analysis was undertaken on all third/fourth degree tears between 2009 and 2011.

Results 361 cases (2.2\% of vaginal births) of third/fourth degree were identified, 182 were $3 \mathrm{~A}$ tears. Information was available for $96 / 182$ women at twelve week postnatal follow-up, overall 78/96 (81\%) had EAUS and 68/96 (71\%) were asymptomatic.

Of the women who had EAUS, 56/68 (82\%) were asymptomatic and $22 / 28$ (79\%) were symptomatic, $49 / 56(88 \%)$ and 19/22 (86\%) respectively had no observable defect.

$17 / 96$ women with $3 \mathrm{~A}$ tears went on to have subsequent pregnancies. 15/17 (88\%) delivered vaginally. All women with EAUS identified sphincter defects delivered vaginally. $66 \%$ of symptomatic women delivered vaginally.

Conclusion Our third degree tear rate is within expected limits. Flatal/faecal incontinence is a poor indicator for the presence of a significant sphincter defect on EAUS. Neither symptoms nor detection of sphincter defect appears to influence subsequent management or mode of birth, therefore the use of this invasive test is of questionable clinical benefit.

\section{PP.83 CAN WE PREDICT POOR PREGNANCY OUTCOMES IN WOMEN PRESENTING WITH REDUCED FETAL MOVEMENTS?}

doi:10.1136/archdischild-2013-303966.358

K Skorupskaite, C Love. New Royal Infirmary of Edinburgh, Edinburgh, UK

Objectives Reduced fetal movements (RFM) are associated with adverse pregnancy outcomes, including intrauterine growth restriction (IUGR) and stillbirth. The aim was to review risk factors which could predict poor perinatal outcomes in women presenting with RFM.

Methods A retrospective patient record review was performed of women presenting to a Scottish tertiary centre with RFM during November 2011.

Results 118 women were assessed for RFM. The study population had the majority of risk factors known to be associated with 